\title{
Application of MASNUM Wave Model in Indo Pacific Ocean and its Verification using Altimeter Data
}

\author{
KUSWARDANI Rita Tisiana Dwi ${ }^{1}$, QIAO FangLi ${ }^{2}$ \\ ${ }^{1}$ Research and Development Center for Marine and Coastal Resources, Agency for Marine and Fisheries Research and Development, Jalan \\ Pasir Putih 1, Ancol Timur, Jakarta 14430
}

${ }^{2}$ First Institute of Oceanography, State Oceanic Administration, Qingdao 266061, China

\begin{abstract}
A long time series of ocean wave in-situ observations is rare and mostly unavailable. An urgent demand for a long time series of ocean wave hindcast and prediction makes attention is shifted to the use of numerical wave model. Wave spectral models then used to generate and estimate the ocean wave. A wave spectral model, MASNUM, was set up to carry out wave hindcast experiments in the Indian Ocean and western Pacific. The model has been run for 6 years and validated by comparing the results with altimeter data from Jason-1. A various statistical methods have been employed to quantify the validation. The lateral boundary is influenced to large error in the model. The RMSE can be reduced about $0.4 \mathrm{~m}$ after rejected the lateral boundary. The error is larger in boreal winter than that in boreal summer.
\end{abstract}

Keywords: ocean wave, hindcast, forecast, numerical model, altimetri

\section{Background}

Long term in-situ ocean observations in the Indian Ocean and western part of Pacific are mostly focused on oceanatmosphere phenomena and tsunami, the observation for ocean wave unavailable [1,2]. The ocean wave data are important for ship navigation, naval operation and offshore structure construction. In recent years, a numerical model is mostly used to generate wave data to get information for long term ocean wave hindcast and forecast.

In recent years, many spectral wave models are used for hindcast and forecast, such as WAVEWATCH III which has been used to calculate coastal wave in Australia [3], advanced for nearshore [4] and used to develop a new forecast model for NCEP [5]. Another spectral wave model MIKE 21 SW developed by DHI (Danish Hydraulic Institute) has carried out wave prediction and hindcast in Indian Ocean [6]. MASNUM wave number spectral model , the third generation of wave model which was developed in early 1990 by LAGFD (Laboratory of Geophysical Fluid Dynamics), FIO (First Institute of Oceanography) of SOA (State Oceanic Administration of China) is used for this study.

LAGFD was renamed as MASNUM in 1997. The model was set up in order to evaluate the wave-induced mixing in the upper ocean and the impact of surface waves on oceanatmosphere fluxes. The model is in spherical coordinates for global and regional areas [7]. The MASNUM wave model has been implemented as forecast model in northwest Pacific validated with Jason-1 altimeter data and data observation from National Data Buoy Center (NDBC) with mean absolute error (MAE) between the forecast significant wave height and observation are $0.5 \mathrm{~cm}$ [8]. The model also has been using as forecast system to produce ocean state data for global oceans, the Northwestern Pacific ocean and the seas adjacent and the China with accurate forecast output [9].
Now, the model is employed to development a wave hindcast and forecast experiments in the Indian ocean and western Pacific. The model results also can be used to provide boundary condition for set up smaller domain model.

\section{Materials and Methods}

For this study, the model domain for wave simulation covers the area $\left(20^{\circ} \mathrm{S}-50^{0} \mathrm{~N}, 30^{\circ} \mathrm{E}-150^{\circ} \mathrm{E}\right)$ and the horizontal resolution is $1 / 6^{0}$ latitude by $1 / 6^{0}$ longitude (Fig.1). Wang et al ${ }^{[10]}$ parallelized this model and recently is developing parallelization method (MPI - Message Passing Interface) using Single Program Multiple Data (SPMD) method. The topography of the wave model is interpolated based on the global 5' x 5' Etopo 5.

The wind data is taken from 6 hourly NCEP/NCAR reanalysis wind field from the global dataset with $1.875^{\circ}$ grid resolution and interpolated into $1 / 6^{0}$ latitude by $1 / 6^{0}$ longitude. The data is provides for $\mathrm{U}$ and $\mathrm{V}$ respectively.

The Significant Wave Height (SWH or Hs) data to validate the wave model are altimeter data from Jason-1 provided by AVISO

(http://www.aviso.oceanobs.com/es/data/index.html). The data provided since 2002 until now. The wave validation was done for 6 years (2003 - 2008). The simulated Hs is compared with the Jason-1 data. Firstly, the satellite time (days, seconds and microseconds summed from 1958.1.1.0.0.0.) is transformed to ordinary temporal coordinate (year, month, day, hour, minute). Secondly, the simulated Hs is interpolated in space and time to the exact satellite observation point. The linear interpolation method is used. For the last step, we calculate the Mean Error (ME), Mean Absolute Error (MAE) and RMSE (Root Mean Square Error). 


\section{International Journal of Science and Research (IJSR) \\ ISSN (Online): 2319-7064 \\ Index Copernicus Value (2013): 6.14 | Impact Factor (2014): 5.611}

The model simulations are recorded 6 hourly and the satellite observations are from the JASON-1 altimetry satellites with a cycle period of 9.916 days. This means that the satellite repeatly observes the same location approximately every 10 day. The satellite use the radar principle to measure the SWH, height of the sea surface and wind speed. The SWH observations from the $k u$ band is used for the validation.

Various statistical methods are used to calculate model error.

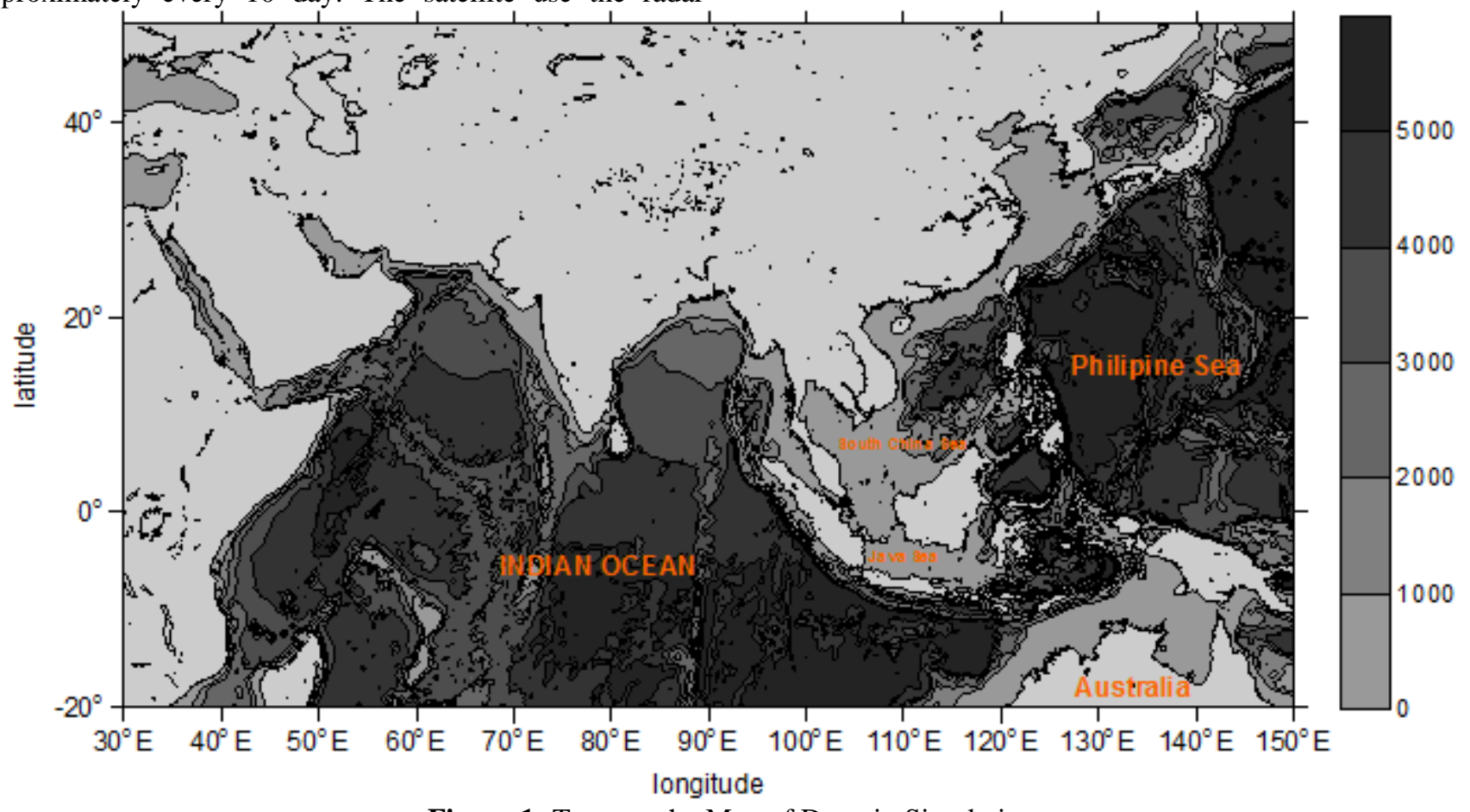

Figure 1: Topography Map of Domain Simulation

\section{Results and Discussion}

The validation was done in two parts, for the whole domain $\left(20^{\circ} \mathrm{S}-50^{\circ} \mathrm{N}, 30^{\circ} \mathrm{E}-150^{\circ} \mathrm{E}\right)$ (hereafter referred as A) and the second we reject the region near lateral boundary and analyze the error for $\left(10^{0} \mathrm{~S}-40^{0} \mathrm{~N}, 20^{\circ} \mathrm{E}-140^{\circ} \mathrm{E}\right)$ (hereafter referred as $\mathrm{B}$ ). The validation for $\mathrm{A}$ and $\mathrm{B}$ give different results. Both validation shows that ME, MAE and
RMSE are higher during SEM (May -September) than those in NWM. The error in validation $A$ is higher than that in validation B. In validation A, RMSE is about $0.61-0.94 \mathrm{~m}$ while in validation $\mathrm{B}$, after we reject the region near lateral boundary, the RMSE is reduced to $0.53-0.68$. The high error in validation A should come from the lateral boundary.

Table 1: The statistical errors between simulation Hs and the data derived from Jason-1 (monthly average from 2003 - 2008 , units in meters)

\begin{tabular}{|c|c|c|c|c|c|c|}
\hline & \multicolumn{2}{|c|}{$\begin{array}{c}\text { ME } \\
\text { (Mean Error) }\end{array}$} & \multicolumn{2}{c|}{$\begin{array}{c}\text { MAE } \\
\text { (Mean Absolute Error) }\end{array}$} & \multicolumn{2}{c|}{$\begin{array}{c}\text { RMS } \\
\text { (Root Mean Square) }\end{array}$} \\
\hline Months & Domain A & Domain B & Domain A & Domain B & Domain A & Domain B \\
\hline January & -0.33 & -0.03 & 0.48 & 0.38 & 0.63 & 0.56 \\
\hline February & -0.35 & -0.06 & 0.54 & 0.38 & 0.70 & 0.54 \\
\hline March & -0.40 & -0.06 & 0.58 & 0.39 & 0.77 & 0.57 \\
\hline April & -0.47 & -0.06 & 0.61 & 0.37 & 0.77 & 0.54 \\
\hline May & -0.61 & -0.14 & 0.72 & 0.39 & 0.89 & 0.56 \\
\hline June & -0.55 & -0.10 & 0.69 & 0.42 & 0.86 & 0.57 \\
\hline July & -0.58 & -0.13 & 0.72 & 0.44 & 0.90 & 0.64 \\
\hline August & -0.60 & -0.14 & 0.71 & 0.43 & 0.88 & 0.62 \\
\hline September & -0.63 & -0.10 & 0.75 & 0.46 & 0.94 & 0.69 \\
\hline October & -0.53 & -0.06 & 0.63 & 0.41 & 0.79 & 0.59 \\
\hline November & -0.42 & -0.04 & 0.53 & 0.38 & 0.68 & 0.55 \\
\hline December & -0.32 & -0.02 & 0.47 & 0.44 & 0.61 & 0.65 \\
\hline
\end{tabular}




\section{International Journal of Science and Research (IJSR) \\ ISSN (Online): 2319-7064}

Index Copernicus Value (2013): 6.14 | Impact Factor (2014): 5.611

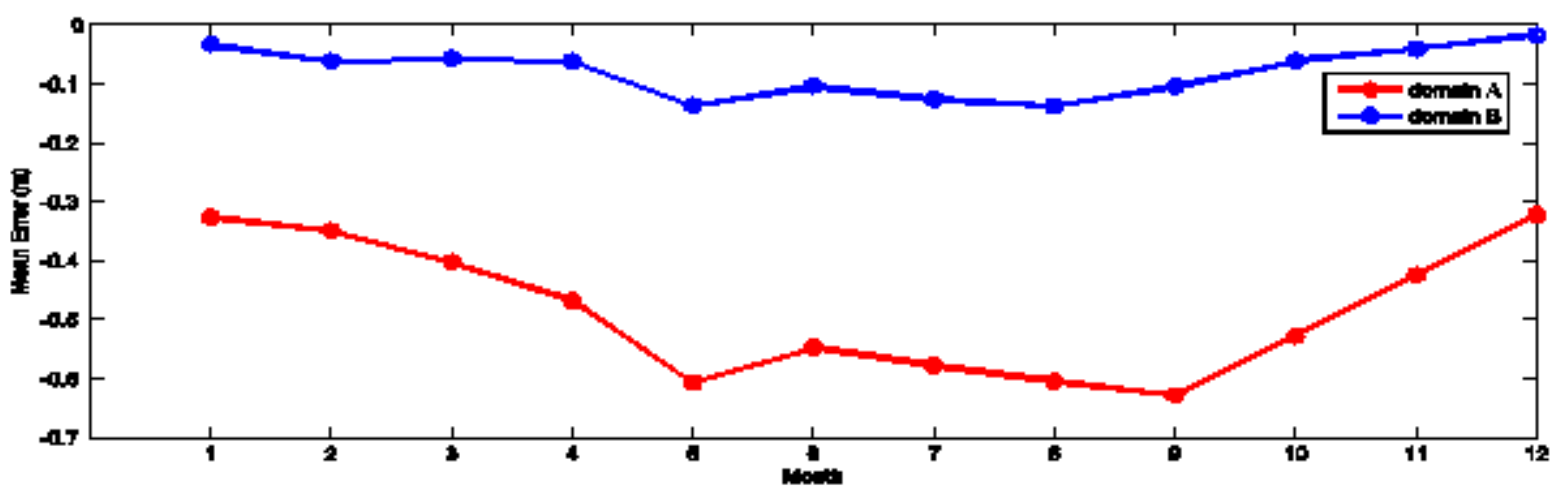

(a)

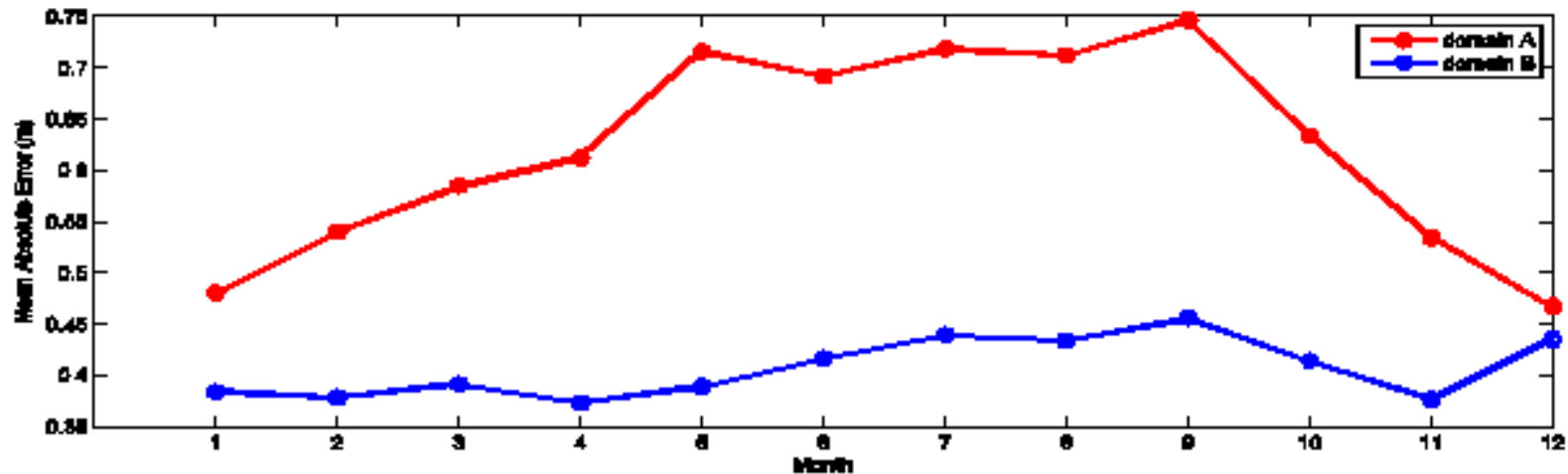

(b)

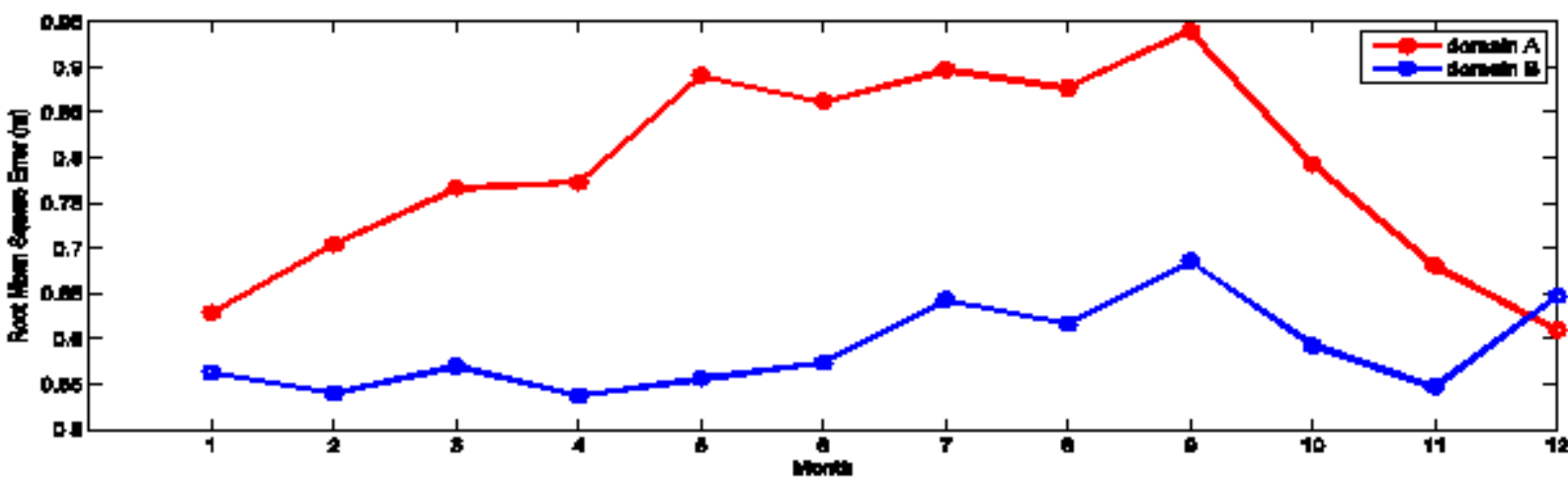

(c)

Figure 2: The statistical errors between simulation Hs and the data derived from Jason-1 (monthly average from 2003 2008 ) for different domain areas of $\mathrm{A}\left(20^{\circ} \mathrm{S}-50^{\circ} \mathrm{N}, 30^{\circ} \mathrm{E}-150^{\circ} \mathrm{E}\right)$ and $\mathrm{B}\left(10^{\circ} \mathrm{S}-40^{\circ} \mathrm{N}, 20^{\circ} \mathrm{E}-140^{\circ} \mathrm{E}\right)$. (a) Mean Error, (b) Mean Absoluter Error, and (c) Root Mean Square Error

The scatter error (Figures 2-7 and 2-8) shows comparison of the Hs between MASNUM wave model and Jason-1 data for domain B. All pairs of MASNUM data for 6 years (2003 2008) and satellite observations has been used. The number of observations in each $4 \times 4 \mathrm{~cm}$ box is shown with colors. The red line represents the best fit to the data. The composite figures are monthly results for 6 years. The scatter plot reflect the fact that both satellite SWH data and model have error which are most pronounced during the boreal winter.
As mentioned above, the scatter plot shows that the data in boreal summer (June, July and August) are more accurate than other months. The SWH at the boundary between land and water may cause the large error since the computation domain contains large number of lands and islands. The error in interpolation for both data (model simulation and satellite) also may cause the error for the model. 
International Journal of Science and Research (IJSR)

ISSN (Online): 2319-7064

Index Copernicus Value (2013): 6.14 | Impact Factor (2014): 5.611

ME : -0.035, MAE : 0.38, RMS : ME : -0.062, MAE : 0.38, RMS 0.56

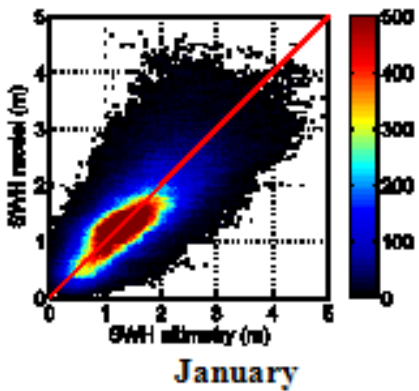

ME : $-0.035, \mathrm{MAE}: 0.38, \mathrm{RMS}$ 0.56

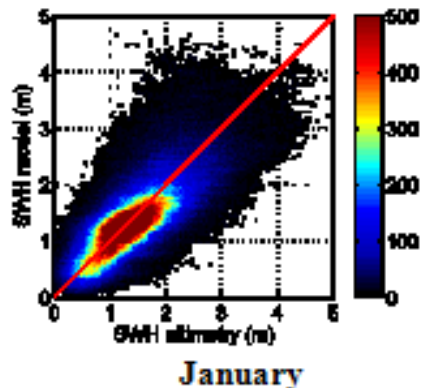

January

ME : -0.062, MAE : 0.37, RMS : 0.54

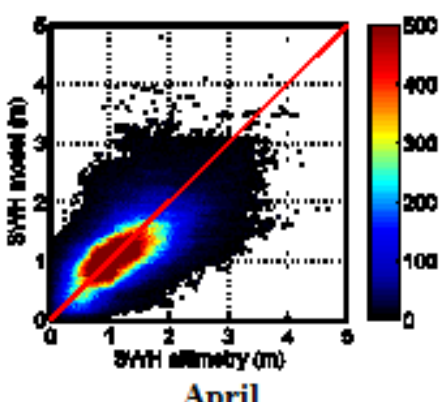

April

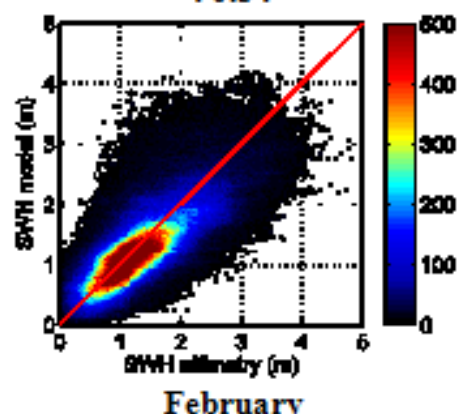

February

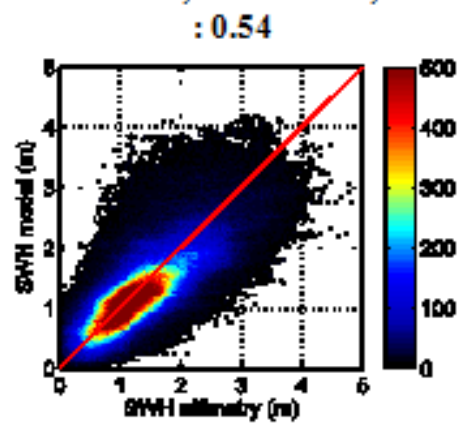

February

ME : $-0.14, \mathrm{MAE}: 0.39, \mathrm{RMS}$ : 0.56

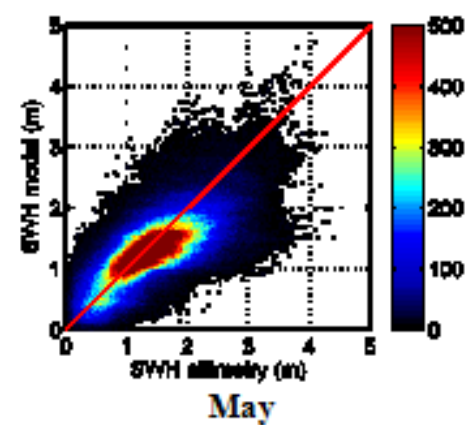

ME : $-0.057, \mathrm{MAE}: 0.39, \mathrm{RMS}$ : 0.57

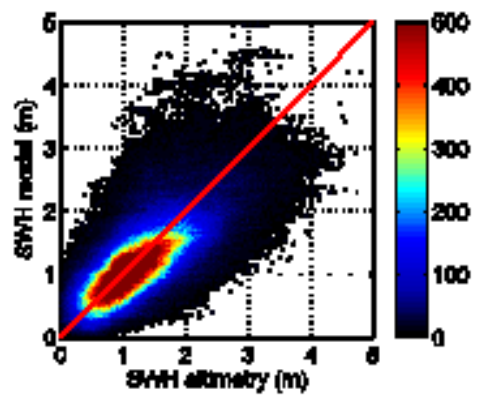

March

ME : -0.057, MAE : 0.39, RMS : 0.57

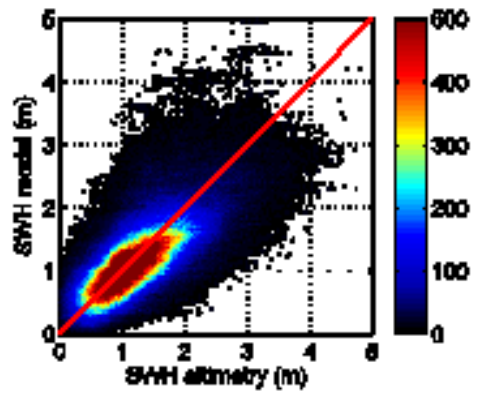

March

ME : $-0.10, \mathrm{MAE}: 0.41, \mathrm{RMS}:$ 0.57

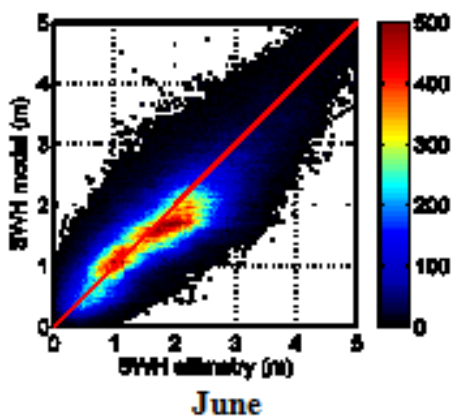

Figure 3: Significant wave height monthly (January to June) composite scatter plot error for 6 years data (2003 - 2008) between the MASNUM wave model and Jason-1 satellite data

ME : $-0.125, \mathrm{MAE}: 0.44, \mathrm{RMS} \quad \mathrm{ME}:-0.14, \mathrm{MAE}: 0.43$, RMS : $: 0.64$

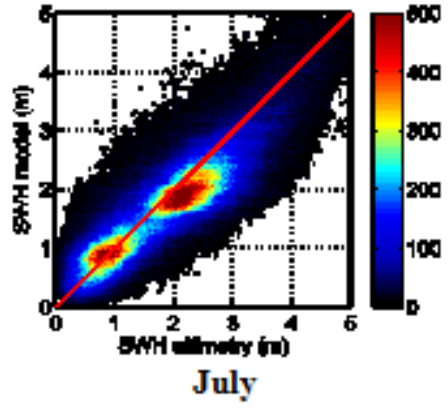

0.62

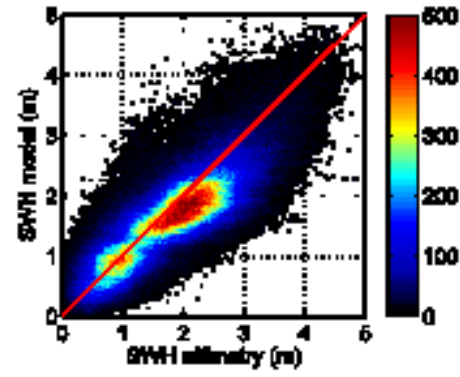

August
ME : -0.104, MAE : 0.455, RMS $: 0.67$

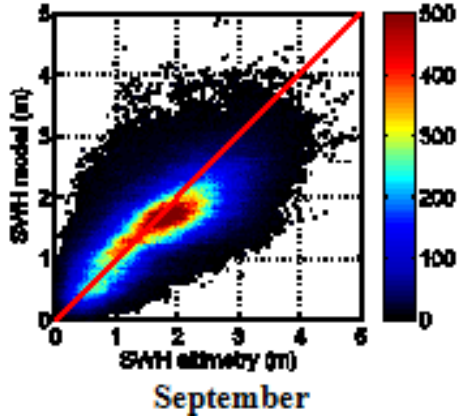




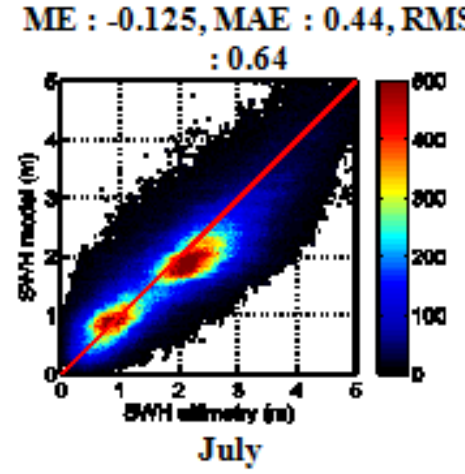

ME : -0.061, MAE : 0.376 , RMS : 0.59

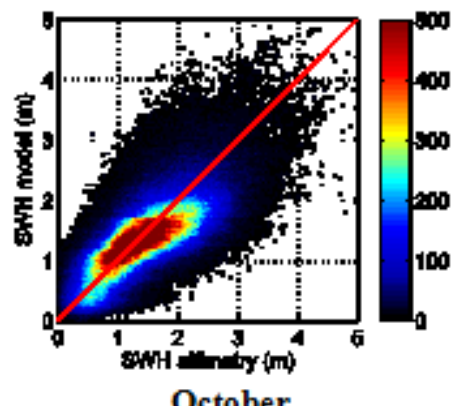

ME : $-0.14, \mathrm{MAE}: 0.43, \mathrm{RMS}$ :

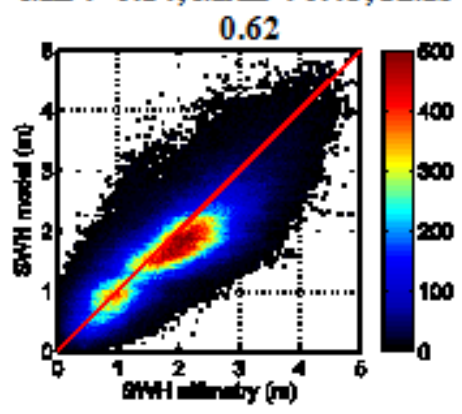

August

ME : -0.041, MAE : 0.43, RMS : 0.55

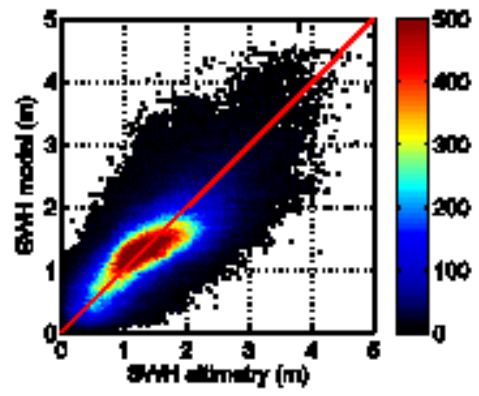

November
ME : $-0.104, \mathrm{MAE}: 0.455, \mathrm{RMS}$

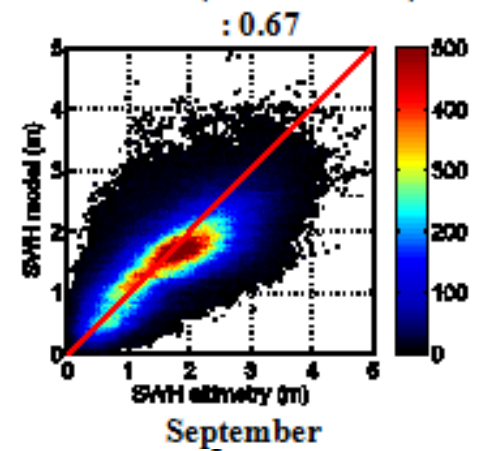

ME : $-0.017, \mathrm{MAE}: 0.43, \mathrm{RMS}$ 0.65

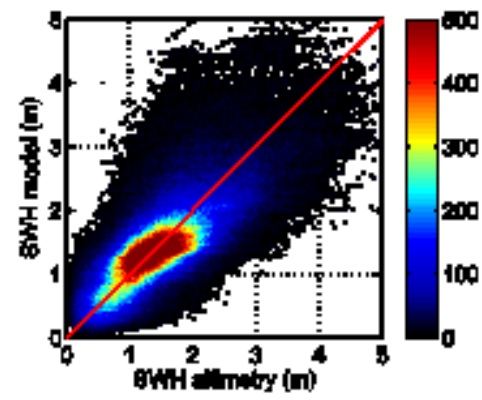

December

Figure 4: Same as Fig 3 but for July - December

\section{Conclusions}

Significant Wave Height (SWH) from the wave model was compared with altimeter data of Jason-1. The wave model validations show that the lateral boundary areas have larger error compared with the interior area, which indicate the importance of accurate boundary conditions and swell since the lateral may be not correctly simulated near boundary area. The RMSE can be reduced about $0.4 \mathrm{~m}$ after rejected the lateral boundary. The error is larger in boreal winter than that in boreal summer.

\section{Acknowledgement}

Rita Tisiana Dwi Kuswardani was supported by the China Scholarship Council during her stay at the Ocean University of China and the First Institute of Oceanography, SOA, China during 2009-2012. The research is supported by the 973 Project (Grant 2010CB950300).

\section{References}

[1] Mc.Phaden, M.J., Meyers, G., Ando, K., Masumoto, Y., Murty, V.S.N., Ravichandran, M., Syamsudin, F., Vialard,Y., Yu, L., Yu, W (2009) RAMA The Research Moored Array for African-Asian-Australian Monsoon Analysis and Prediction, American Meteorological Society, DOI:10.1175/2008BAMS2608.1

[2] Pandoe, W.W. Djamaludin, R., Handoyo, S., Kongko, W (2008) The 12 September 2007 Tsunami Detected on On Indonesian 'Krakatau' Tsunameter, International
Conference on Tsunami Warning (ICTW), Bali, Indonesia.

[3] Bosserelle, C., Pattiaratchi, C. and Haigh, I.D. (2012), Inter-annual variability and longer-term changes in the wave climate of Western Australia between 1970 and 2009, Ocean Dynamics 62, 63-76.

[4] Andre J. van der Westhuysen: (2012) Modeling nearshore wave processes, ECMWF Workshop on Ocean Waves, 25-27 June 2012, 20 pp

[5] Arun Chawla, Deanna Spindler, Hendrik Tolman: (2011): WAVEWATCH III Hindcasts with Re-analysis windsâ $\square$. Initial report on model setup

[6] Remya, P.J., Kumar, R., Basu, S., Sharkar, A (2012) Wave Hindcast Experiment in Indiian Ocean using MIKE 21 SW model, J. Earth Syst. Sci. 121, No. 2,, pp. 385-392

[7] Yang,Y.Z., Qiao, F.L., Zhao, W., Teng, Y., Yuan, Y.L (2005) MASNUM Ocean Wave Numerical Model in Spherical Coordinates and its Application, Acta Oceanologica Sinica, Vol 27, No.2, pp. 2-7 (in Chinese)

[8] Sun Y.J., Qiao, F.L., Wang, G.S., Yin, X.Q., Yang, Y.Z (2009) Forecast Operation and Verification of MASNUM Surface Wave Numerical Model, Acta Oceanologica Sinica, Vol 27, No.3 , pp 281-294 (in Chinese)

[9] Zhang, Q., Wang, Y., Wang, G.S., Zhang, T., Yang, Y.Z (20 ) Operation and Verification for a Wave-TideCurrent Coupling Numerical Forecast System with Fine Resolution, Acta Oceanologica Sinica, Vol 29, No,2, pp 129-136 (in Chinese) 